\title{
Survey of Food-hygiene Practices at Home and Childhood Diarrhoea in Hanoi, Viet Nam
}

\author{
Kumiko Takanashi',2,Yuko Chonan', Dao To Quyen³, Nguyen Cong Khan, \\ Krishna C. Poudel', and Masamine Jimba' \\ 'Department of Community and Global Health, Graduate School of Medicine, University of Tokyo, Japan, ${ }^{2}$ International Life \\ Sciences Institute Japan Center for Health Promotion, Japan, and ${ }^{3}$ National Institute of Nutrition, Hanoi,Viet Nam
}

\begin{abstract}
A cross-sectional study was conducted to investigate the potential factors of food-hygiene practices of mothers on the prevalence of diarrhoea among their children. Mothers who had children aged 6 months-5 years were recruited in a hamlet in Viet Nam. The food-hygiene practices included hand-washing, method of washing utensils, separation of utensils for raw and cooked food, and the location where foods were prepared for cooking. A face-to-face interview was conducted, and data on 206 mothers were analyzed. The risk of diarrhoea was significantly higher among children whose mothers prepared food for cooking somewhere other than the table (typically on the ground) compared to children whose mothers prepared food on the table (adjusted odds ratio $=2.85,95 \%$ confidence interval 1.11-7.28). The results indicate that food-hygiene practices of mothers, such as avoiding preparing food for cooking on the ground, has a potential impact in preventing diarrhoea among children in Viet Nam.
\end{abstract}

Key words: Cross-sectional studies; Diarrhoea; Diarrhoea, Infantile; Food handling; Hygiene; Knowledge, attitudes, and practice; Viet Nam

\section{INTRODUCTION}

The prevention of diarrhoea remains one of the major public-health problems in developing countries. Approximately 1.5 billion episodes of diarrhoea are reported every year in developing countries, and this figure has remained more or less constant over the last 20 years (1). An estimated 2.5 million people die due to diarrhoea each year, and the majority are children aged less than five years in developing countries (2).

The prevalence of diarrhoea among children aged less than five years is also a concern in Viet Nam. Diarrhoea morbidity among this age-group in Viet Nam was $11.3 \%$ in 2000 (3). The estimated annual number of children who died due to diarrhoea was 7,900 (4). Furthermore, diarrhoea can cause mal-

Correspondence and reprint requets should be addressed to:

Dr. Masamine Jimba

Department of Community and Global Health

Graduate School of Medicine

University of Tokyo

7-3-1 Hongo, Bunkyo-ku

Tokyo 113-0033, Japan

Tel: 81358413698

Email: mjimba@m.u-tokyo.ac.jp

Fax: 81358413422 nutrition, leading to impaired physical growth and cognitive development $(5,6)$. Therefore, prevention of diarrhoea is as important as its treatment.

Inadequate food hygiene is considered to be one of the major contributors to diarrhoea. Up to 70\% of diarrhoea episodes in developing countries are regarded as food-borne (7-9). Weaning food given to children in West Africa (10-11), Bangladesh (12), and Peru (13) contains substantial amounts of bacteria.

The level of food contamination is related to the storage of foods at high ambient temperature (12), for long periods of time $(10,11,14)$, and in the rainy season $(10,15)$. Unclean utensils were also considered a source of food contamination $(9,16,17)$.

Furthermore, previous studies have shown that several food-hygiene factors are associated with diarrhoea among children. For example, results of a prospective cohort study in Turkey showed that infants whose houses did not have a kitchen were more likely to suffer from diarrhoea (18). Similarly, children in Nigeria who lived in households with a private kitchen had lower incidence rates of diarrhoea than those whose households had no such kitchens (19). Results of a case-control study in Bra- 
zil showed that owners of refrigerators were more likely to have a lower rate of diarrhoea among children (20). The hand-washing practice of mothers before food preparation was also associated with a lower risk of diarrhoea among children (21-23). The prevalence of diarrhoea among children was significantly higher in families where mothers less often washed their hands before feeding children in a case-control study in Viet Nam (24). For children's practices, eating food that had been placed on the floor was significantly associated with persistent diarrhoea in a case-control study in Myanmar (25). The cleanliness of kitchen-floor was significantly associated with the prevalence of diarrhoea among children in Nicaragua (21).

Although the World Health Organization (WHO) outlined basic principles for the preparation of safe food for infants and young children (7), little has been reported on the effect of food-hygiene practices of mothers on diarrhoea among children in community settings $(26,27)$. Therefore, more data should be collected to describe the potential factors of food-hygiene practices of mothers on diarrhoea among children in Viet Nam. The data will be useful to develop guidelines fit for local setting and to encourage mothers to change their practices for preventing diarrhoea among children.

The objective of this study was to investigate the potential factors of food-hygiene practices of mothers in the home on the prevalence of diarrhoea among their children in a community in Hanoi, Viet Nam.

\section{MATERIALS AND METHODS}

\section{Study site}

The study was conducted in Huynh Cung village, Tam Hiep commune, Thanh Tri district, Hanoi city, Viet Nam. Thanh Tri district is categorized as one of five sub-urban districts of 14 districts of Hanoi city and located in the low-lying Red Delta region, with an average elevation of 3-4 metres. Its main products are rice, flowers, and vegetables. The average annual income per household was about US\$ 400 in 2004 (28). This commune consists of three hamlets. One of them-the Huynh Cung hamlet-had a population of about 3,900 in 2006.

Water supply and sanitation at the study site

The water-treatment facility (WTF) has been distributing water to the Huynh Cung hamlet but it has not succeeded in removing iron, arsenic, and ammonium from the water supply (29). Further- more, contamination by coliforms and Clostridium perfringens was also detected (29). A municipal sewage system does not exist in this hamlet.

\section{Participants}

The study team recruited all mothers with children aged 6 months -5 years in the target area. This criterion was used since children aged less than five years were considered to be more affected by unhygienic water condition. Children younger than six months were excluded as most of them were breastfed and had less exposure to drinking-water. In total, 298 children were selected in the hamlet, using the register of the hamlet. In cases where more than two children in the selected age-group belonged to one household, the youngest child was targeted in this study. The three collaborators (non-salaried, volunteer health workers) of the commune health station took informed consent from the targeted mothers before data collection, and all the 298 mothers agreed to participate in the survey.

During the three-day survey period, however, only 235 mothers came to the commune health station and registered to participate in the survey. The common reasons of absence were: forgetting the survey date, having other work, and waiting too long to register. Furthermore, 14 other caretakers, such as grandmothers and fathers who came to the survey, instead of mothers, were excluded. Of the registered 235 mothers, 213 (90.6\%) were interviewed because they had registered with more than two children in one household, or they left without receiving the interview. Seven additional mothers were excluded for minor reasons (e.g. on the interview day, age of their children was found to be more than 5 years). The remaining 206 mothers were included in data analysis.

\section{Data collection}

Data were collected as part of a baseline survey in a project for improving water and nutrition in northern Viet Nam from 2001 to 2008. The project has been implemented by the National Institute of Nutrition (NIN), the International Life Sciences Institute Japan Center for Health Promotion (ILSI Japan CHP), and the Japan International Cooperation Agency (JICA).

A structured questionnaire, used for conducting interviews, consisted of four sections: (a) general information, (b) nutrition and health, (c) food hygiene, and (d) water management in the household, with total 113 items. The questionnaire was 
prepared mainly based on a similar survey (30) and the guidelines set by the WHO (7) and the Viet Nam government authority (31). The questionnaire was also developed based on information from staff members of the commune health station, the leader of the hamlet, the leader of the commune, and two group discussions: one with 10 mothers and another with 10 men living in the hamlet.

Several food-hygiene practices of mothers were measured. Such practices included hand-washing before food preparation, washing-method of utensils, such as cups, bowls, and spoons, separation of utensils, such as cutting boards or knives for raw or cooked food, and the location where food was prepared for cooking. We also recorded the episodes of childhood diarrhoea). Childhood diarrhoea was defined as the percentage of children who experienced watery stool more than three times per day in the past two weeks before the survey $(32,33)$.

A pre-test was conducted with 25 participants in December 2005 in two different hamlets of the Tam Hiep commune. Additional modification was made based on the results of the pre-test. The questionnaire was originally developed in English. A Vietnamese staff member working at the NIN translated the English questionnaire into Vietnamese. Another professional translator did back-translation to confirm the meaning.

Trained eight interviewers from the NIN conducted a face-to-face interview with the mothers at the commune health station from 15 to 17 January 2006. Each interview took 20-30 minutes.

The study received an ethical approval from the Institutional Review Board of the University of Tokyo. The NIN also approved the study and gave ethical clearance.

\section{Analysis of data}

The Epi Info software (version 2000) was used for data input and the SPSS software (version 12.0J) (SPSS, Japan Inc., Tokyo) for data analysis. First, we described the prevalence of childhood diarrhoea and the food-hygiene practices. Then, we performed bivariate analysis to examine the relationships between the food-hygiene practices of mothers and the prevalence of childhood diarrhoea. Finally, multiple logistic regression analysis was performed to adjust for the confounding factors to examine a relationship between the food-hygiene practices and the prevalence of diarrhoea among children. The diarrhoea-prevalence variable was adjusted for confounding factors, such as age of child, gender, education of mother, hand-washing by the child with soap after toilet, hand-washing by the child with soap before eating, hand-washing by the mother with soap after toilet, and hand-washing by the mother with soap before feeding. We adjusted these variables as they were associated with childhood diarrhoea in previous studies $(9,20,22$ 25,34-38). In this study, possession of a refrigerator was also considered to reflect the economical status of household; therefore, we also included this variable in the model. We reported the odds ratio (OR) of diarrhoea among children and 95\% confidence interval (CI).

\section{RESULTS}

\section{Characteristics of children and their mothers}

The mean age of 206 children was 27.7 (standard deviation $[\mathrm{SD}]=15.0)$ months: $71.3 \%$ were aged 6 months-2 years. In all, 115 (55.8\%) were male (Table 1). The number of first-born or second-born children was 199 (96.6\%). All children had started receiving some additional food or drink other than breastmilk before the survey period. Overall, 46 $(22.7 \%)$ children had diarrhoea at least once in the past two weeks before the interview (Table 1). The mean age of the mothers was $30.5(\mathrm{SD}=4.8)$ years. Regarding the education of mothers, 200 (98.0\%) attended at least secondary school (grade 6-9), and 129 (63.2\%) attended at least high school (grade 1012) (Table 1). Overall, 68 (34.5\%) mothers worked as farmers. Twenty-nine (14.7\%) mothers were housewives. For the question "who takes care of the child most frequently?", 168 (76.4\%) answered 'mother', and 38 (17.3\%) answered 'grandmother'. The mean number of family members was 4.6 $\pm \mathrm{SD}=1.5$. $63.1 \%$ had refrigerators.

\section{Status of sanitation, water management, and hand-washing}

Table 2 shows the condition of sanitation, water management, hand-washing practices, and foodhygiene practices. In terms of sanitation, nearly all (205 of 206) households had a private toilet, and of these, $159(77.6 \%)$ had a water-flush toilet. The water-flash toilet has an underground tank and is flushed by pouring in a bucket of water. Forty-one (20\%) had the sewage-tank of single/double vault latrine, which is located on the ground, and faeces are used as fertilizer for agriculture. Five (2.4\%) used biogas vault latrine or septic tank. As for water management, the households in the hamlet used several water sources, such as water from watertreatment facility, private wells, rainwater for drink- 


\begin{tabular}{|c|c|c|}
\hline Characteristics & No. & $\%^{*}$ \\
\hline \multicolumn{3}{|l|}{ Children } \\
\hline \multicolumn{3}{|l|}{ Age (years) } \\
\hline 0 & 31 & 15.0 \\
\hline 1 & 67 & 32.5 \\
\hline 2 & 49 & 23.8 \\
\hline 3 & 31 & 15.0 \\
\hline 4 & 28 & 13.6 \\
\hline \multicolumn{3}{|l|}{ Gender } \\
\hline Male & 115 & 55.8 \\
\hline Female & 91 & 44.2 \\
\hline \multicolumn{3}{|l|}{$\begin{array}{l}\text { Diarrhoea experience during } 2 \\
\text { weeks before survey }{ }^{\dagger}\end{array}$} \\
\hline Experienced & 46 & 22.7 \\
\hline Not experienced & 157 & 77.3 \\
\hline \multicolumn{3}{|l|}{ Mothers } \\
\hline \multicolumn{3}{|l|}{ Education $\neq$} \\
\hline $\begin{array}{l}\text { Primary school/secondary } \\
\text { school }\end{array}$ & 75 & 36.8 \\
\hline $\begin{array}{l}\text { High school/college/ } \\
\text { university }\end{array}$ & 129 & 63.2 \\
\hline \multicolumn{3}{|l|}{ OccupationI } \\
\hline Farmer/housework & 97 & 49.2 \\
\hline Others (worker, teacher, etc) & 100 & 50.8 \\
\hline \multicolumn{3}{|l|}{ Possession of refrigerator } \\
\hline No & 76 & 36.9 \\
\hline Yes & 130 & 63.1 \\
\hline
\end{tabular}

* Sum of individual proportions may not add up to $100 \%$ due to rounding; †Participants who did not answer this question $(\mathrm{n}=3)$ were excluded from the analysis; $¥$ Participants who did not answer this question $(n=2)$ were excluded from the analysis; IParticipants who did not answer this question $(n=9)$ were excluded from the analysis

ing purpose but 204 (99.0\%) boiled water before drinking.

Finally, analysis of hand-washing practice of children revealed that $36.8 \%$ of the 182 mothers reported that hands of children were always washed with soap after using the toilet, and $29.7 \%$ of the 192 mothers reported that hands of children were always washed with soap before eating. Two hundred six mothers (59.2\%) always washed their hands with soap after using the toilet, and 206 (43.2\%) mothers always washed their hands with soap before feeding.

\section{Status of food-hygiene practices}

Table 2 shows that 206 (30.1\%) mothers always washed their hands with soap before preparation of foods. For washing utensils, 205 (86.8\%) mothers always washed utensils by water with soap. Eightyseven (42.4\%) of the 205 mothers did not separate utensils for raw or cooked food, and 58 (28.2\%) mothers did not always prepare foods for cooking on the table. Of the 58 mothers, $52(89.7 \%)$ prepared foods for cooking always on the ground, and five $(8.6 \%)$ prepared foods for cooking sometimes on the ground.

\section{Association of diarrhoea with age of children}

The prevalence of diarrhoea was $32.3 \%(n=31)$ among children aged less than one year, and it was $31.3 \%(n=67)$ among children aged one year. On the other hand, the prevalence of diarrhoea was $16.7 \%(\mathrm{n}=48)$ among children aged two years. It was $13.8 \%(\mathrm{n}=29)$ among children aged three years and $10.7 \%(\mathrm{n}=28)$ among children aged four years. Its prevalence was significantly higher among children aged less than two years than among children aged 2-4 years (odds ratio [OR] $=2.78,95 \%$ (confidence interval [CI] 1.39-5.55) (Table 3).

\section{Association between diarrhoea and food-hygiene practices}

Table 3 shows that the two variables, which showed significant associations with the prevalence of diarrhoea and food-hygiene practices, were: separation of utensils for raw and cooked food and the place of preparing foods for cooking in a bivariate analysis. The risk of diarrhoea was significantly higher among children whose mothers did not separate utensils for raw and cooked food compared to children whose mothers did separate the utensils $(\mathrm{OR}=2.03,95 \% \mathrm{CI} 1.04-3.94)$. The risk of diarrhoea was also significantly higher among children whose mothers did not prepare foods for cooking on the table compared to children whose mothers did prepare foods for cooking on the table (OR=2.50, 95\% CI 1.25-4.97). For only the place of preparing foods for cooking, the odds ratios were even higher after adjustment for confounders $(\mathrm{OR}=2.85,95 \% \mathrm{CI}$ 1.11-7.28) (Table 4).

Washing of utensils and the hand-washing practice before preparation of foods did not show any significant association with the prevalence of diarrhoea among children. 


\begin{tabular}{|c|c|c|}
\hline Onsite condition & No. & $\%$ \\
\hline \multicolumn{3}{|l|}{ Sanitation } \\
\hline \multicolumn{3}{|l|}{ Private toilet/latrine ownership } \\
\hline No & 1 & 0.5 \\
\hline Yes & 205 & 99.5 \\
\hline \multicolumn{3}{|l|}{ Type of toilet (among owners of a private toilet) } \\
\hline Water-flush toilet & 159 & 77.6 \\
\hline Single/double vault latrine & 41 & 20.0 \\
\hline Others (biogas vault latrine, septic tank) & 5 & 2.4 \\
\hline \multicolumn{3}{|l|}{ Water } \\
\hline \multicolumn{3}{|l|}{ Water boiled before drinking } \\
\hline Not always & 2 & 1.0 \\
\hline Always & 204 & 99.0 \\
\hline \multicolumn{3}{|l|}{ Hand-washing } \\
\hline \multicolumn{3}{|c|}{ Hand-washing with soap after toilet (children's hands) } \\
\hline Not always water with soap & 115 & 63.2 \\
\hline Always water with soap & 67 & 36.8 \\
\hline \multicolumn{3}{|c|}{ Hand-washing with soap before eating (children's hands) ${ }^{\dagger}$} \\
\hline Not always water with soap & 135 & 70.3 \\
\hline Always water with soap & 57 & 29.7 \\
\hline \multicolumn{3}{|l|}{ Hand-washing with soap after toilet (mothers) } \\
\hline Not always water with soap & 84 & 40.8 \\
\hline Always water with soap & 122 & 59.2 \\
\hline \multicolumn{3}{|c|}{ Hand-washing with soap before feeding (mothers) } \\
\hline Not always water with soap & 117 & 56.8 \\
\hline Always water with soap & 89 & 43.2 \\
\hline \multicolumn{3}{|l|}{ Food-hygiene behaviour } \\
\hline \multicolumn{3}{|c|}{ Hand-washing with soap before food preparation } \\
\hline Not always water with soap & 144 & 69.9 \\
\hline Always water with soap & 62 & 30.1 \\
\hline \multicolumn{3}{|l|}{ Washing utensils $\ddagger$} \\
\hline Not always water with soap & 27 & 13.2 \\
\hline Always water with soap & 178 & 86.8 \\
\hline \multicolumn{3}{|l|}{ Separating utensils for raw and cooked food $\ddagger$} \\
\hline No & 87 & 42.4 \\
\hline Yes & 118 & 57.6 \\
\hline \multicolumn{3}{|l|}{ Place of preparing foods for cooking } \\
\hline Not always on the table & 58 & 28.2 \\
\hline Always on the table & 148 & 71.8 \\
\hline
\end{tabular}

${ }^{*}$ Participants who did not answer this question $(\mathrm{n}=24)$ were excluded from analysis; †Participants who did not answer this question ( $\mathrm{n}=14$ ) were excluded from analysis; $¥$ One participant who did not answer this question was excluded from analysis

\section{DISCUSSION}

The results of this study suggest that food-hygiene practices of mothers might have an important impact on the prevalence of diarrhoea among children. The risk of diarrhoea was higher among chil- dren whose mothers did not separate utensils for raw and cooked food and whose mothers prepared food on the ground rather than on the table. Children aged less than two years were more vulnerable to suffer from diarrhoea than children aged 2-4 years. The association with the prevalence of 


\begin{tabular}{|c|c|c|c|c|c|}
\hline \multirow{3}{*}{ Associated factor } & \multirow{3}{*}{$\begin{array}{c}\text { Total } \\
(\mathrm{n}=203)^{\star}\end{array}$} & \multicolumn{4}{|c|}{ Diarrhoea } \\
\hline & & \multicolumn{2}{|c|}{ Cases } & \multirow{2}{*}{ OR } & \multirow{2}{*}{$95 \%$ CI } \\
\hline & & No. & $\%$ & & \\
\hline \multicolumn{6}{|l|}{ Characteristics of children } \\
\hline \multicolumn{6}{|l|}{ Age (months) } \\
\hline $6-23$ & 98 & 31 & 31.6 & 2.78 & $1.39-5.55$ \\
\hline $24-59$ & 105 & 15 & 14.3 & 1.00 & \\
\hline \multicolumn{6}{|l|}{ Gender } \\
\hline Male & 113 & 31 & 27.4 & 1.89 & $0.95-3.77$ \\
\hline Female & 90 & 15 & 16.7 & 1.00 & \\
\hline \multicolumn{6}{|l|}{ Characteristics of mothers } \\
\hline \multicolumn{6}{|l|}{ Education ${ }^{\dagger}$} \\
\hline Primary school/secondary school & 74 & 21 & 28.4 & 1.62 & $0.83-3.15$ \\
\hline High school/college/university & 127 & 25 & 19.7 & 1.00 & \\
\hline \multicolumn{6}{|l|}{ Possession of refrigerator } \\
\hline No & 75 & 20 & 26.7 & 1.43 & $0.73-2.79$ \\
\hline Yes & 128 & 26 & 20.3 & 1.00 & \\
\hline \multicolumn{6}{|l|}{ Hand-washing } \\
\hline \multicolumn{6}{|c|}{ Hand-washing with soap after toilet (children's hands) } \\
\hline Not always water with soap & 112 & 25 & 22.3 & 1.19 & $0.56-2.53$ \\
\hline Always water with soap & 67 & 13 & 19.4 & 1.00 & \\
\hline \multicolumn{6}{|c|}{ Hand-washing with soap before eating (children's hands) Il } \\
\hline Not always water with soap & 133 & 27 & 20.3 & 0.70 & $0.34-1.44$ \\
\hline Always water with soap & 56 & 15 & 26.8 & 1.00 & \\
\hline \multicolumn{6}{|c|}{ Hand-washing with soap after toilet (mothers) } \\
\hline Not always water with soap & 82 & 16 & 19.5 & 0.74 & $0.37-1.46$ \\
\hline Always water with soap & 121 & 30 & 24.8 & 1.00 & \\
\hline \multicolumn{6}{|c|}{ Hand-washing with soap before feeding (mothers) } \\
\hline Not always water with soap & 115 & 24 & 20.9 & 0.79 & $0.41-1.53$ \\
\hline Always water with soap & 88 & 22 & 25.0 & 1.00 & \\
\hline \multicolumn{6}{|l|}{ Food-hygiene behaviours } \\
\hline \multicolumn{6}{|c|}{ Hand-washing with soap before food preparation } \\
\hline Not always water with soap & 142 & 31 & 21.8 & 0.86 & $0.42-1.74$ \\
\hline Always water with soap & 61 & 15 & 24.6 & 1.00 & \\
\hline \multicolumn{6}{|l|}{ Washing utensils§ } \\
\hline Not always water with soap & 23 & 8 & 34.8 & 2.05 & $0.81-5.19$ \\
\hline Always water with soap & 179 & 37 & 20.7 & 1.00 & \\
\hline \multicolumn{6}{|c|}{ Separating utensils for raw and cooked food§ } \\
\hline No & 87 & 26 & 29.9 & 2.03 & $1.04-3.94$ \\
\hline Yes & 115 & 20 & 17.4 & 1.00 & \\
\hline \multicolumn{6}{|l|}{ Place of preparing foods for cooking } \\
\hline Not always on table & 57 & 20 & 35.1 & 2.50 & $1.25-4.97$ \\
\hline Always on table & 146 & 26 & 17.8 & 1.00 & \\
\hline \multicolumn{6}{|c|}{$\begin{array}{l}\text { *Participants who did not answer the question about diarrhoea }(\mathrm{n}=3) \text { were excluded from analysis; } † \text { Par- } \\
\text { ticipants who did not answer this question }(\mathrm{n}=2) \text { were excluded from analysis; } ¥ \text { Participants who did not } \\
\text { answer this question }(\mathrm{n}=24) \text { were excluded from analysis; IParticipants who did not answer this question } \\
(\mathrm{n}=14) \text { were excluded from analysis; §One participant who did not answer this question was excluded } \\
\text { from analysis; CI=Confidence Interval; OR=Odds ratio }\end{array}$} \\
\hline
\end{tabular}


Table 4. Odds ratios for diarrhoea adjusted for confounding factors

\begin{tabular}{|c|c|c|}
\hline \multirow{2}{*}{ Potential risk factor } & \multicolumn{2}{|c|}{ Diarrhoea } \\
\hline & $\mathrm{AOR}^{*}$ & $95 \% \mathrm{CI}$ \\
\hline \multicolumn{3}{|l|}{ Characteristics of children } \\
\hline \multicolumn{3}{|l|}{ Age (months) } \\
\hline $6-23$ & 1.87 & $0.78-4.48$ \\
\hline $24-59$ & 1.00 & \\
\hline \multicolumn{3}{|l|}{ Gender } \\
\hline Male & 2.40 & $0.95-6.07$ \\
\hline Female & 1.00 & \\
\hline \multicolumn{3}{|l|}{ Characteristics of mothers } \\
\hline \multicolumn{3}{|l|}{ Education } \\
\hline Primary school/secondary school & 2.10 & $0.91-4.88$ \\
\hline High school/college/university & 1.00 & \\
\hline \multicolumn{3}{|l|}{ Possession of refrigerator } \\
\hline No & 1.49 & $0.63-3.54$ \\
\hline Yes & 1.00 & \\
\hline \multicolumn{3}{|l|}{ Hand-washing } \\
\hline \multicolumn{3}{|c|}{ Hand-washing with soap after toilet (children's hands) } \\
\hline Not always water with soap & 2.42 & $0.69-8.52$ \\
\hline Always water with soap & 1.00 & \\
\hline \multicolumn{3}{|c|}{ Hand-washing with soap before eating (children's hands) } \\
\hline Not always water with soap & 0.50 & $0.13-1.88$ \\
\hline Always water with soap & 1.00 & \\
\hline \multicolumn{3}{|c|}{ Hand-washing with soap after toilet (mothers) } \\
\hline Not always water with soap & 0.33 & $0.11-1.04$ \\
\hline Always water with soap & 1.00 & \\
\hline \multicolumn{3}{|c|}{ Hand-washing with soap before feeding (mothers) } \\
\hline Not always water with soap & 1.38 & $0.34-5.61$ \\
\hline Always water with soap & 1.00 & \\
\hline \multicolumn{3}{|l|}{ Food-hygiene behaviours } \\
\hline \multicolumn{3}{|c|}{ Hand-washing with soap before food preparation } \\
\hline Not always water with soap & 0.56 & $0.14-2.21$ \\
\hline Always water with soap & 1.00 & \\
\hline \multicolumn{3}{|l|}{ Washing utensils } \\
\hline Not always water with soap & 2.69 & $0.79-9.20$ \\
\hline Always water with soap & 1.00 & \\
\hline \multicolumn{3}{|c|}{ Separating utensils for raw and cooked food } \\
\hline No & 2.33 & $0.95-5.71$ \\
\hline Yes & 1.00 & \\
\hline \multicolumn{3}{|l|}{ Place of preparing foods for cooking } \\
\hline Not always on table & 2.85 & 1.11-7.28 \\
\hline Always on table & 1.00 & \\
\hline
\end{tabular}

*Age of children, gender, education of mothers, possession of refrigerator, hand-washing of children with soap after toilet, hand-washing by children before eating, hand-washing by mothers with soap after toilet, and hand-washing by mothers with soap before feeding; $\mathrm{AOR}=$ Adjusted odds ratios; $\mathrm{CI}=$ Confidence interval 
diarrhoea could indicate that the food prepared on the ground was contaminated, and the grounds or the floors are the important routes of transmission of diarrhoea pathogens (39).

Conversely, it could suggest the importance of creating barriers to preventing the spread of pathogens from the ground or floors to food. Besides, we have to note that the preparation of food on the ground may per se not be the primary risk factor of diarrhoea among children. However, the findings of the study will be useful for mothers to guide what kind of measures they can take to minimize the risk of potential contamination of food in relation to diarrhoea. The practice of preparing foods on the ground is a common and traditional custom in Viet Nam. However, this custom may increase the possibility of food contamination and could cause diarrhoea in children in Vietnamese households. Our study introduced that cooking on the table is one of the preventive factors in controlling diarrhoea in Viet Nam. Similar practices may be common in many developing countries; therefore, the effort should be made together with thorough cooking and immediate feeding in clean conditions.

The hand-washing practices of the mothers or children were not statistically associated with the prevalence of childhood diarrhoea. In this study, grandmothers most frequently cared about $17 \%$ of the children, and it is possible that the hand-washing practice of grandmothers was different from the practice of our participants. Moreover, we relied on self-report; it is possible that social desirability bias might have influenced the response of our participants on their hand-washing practices.

This study has some limitations. First, although measures were piloted, self-report of hygiene practices are potentially subject to inaccuracy in recall or social desirability bias (40). Therefore, we need further detailed investigation, including household observation. Second, food-hygiene practices include more practices than this study defined. This study missed some important food-hygiene practices, such as food storage and assuring that food is cooked thoroughly at adequately high temperature (41). Further studies are needed to more comprehensively examine the effects of food-hygiene practices on diarrhoea. Third, at the study site, nearly everyone had a toilet, and we found adequate water management (e.g. high rate of boiling water-use). This characteristic may not be typical of other developing countries with high prevalence of diarrhoea among children. However, boiling water was not clearly defined in terms of the time and the temperature.
In conclusion, the results of this study suggest that food-hygiene practices of mothers in the home had a potential impact on the prevention of diarrhoea. The improvement of food-hygiene practices of mothers could be an effective strategy to prevent diarrhoea among children. Further investigation and evaluation studies are needed to document other means of improving food hygiene to prevent diarrhoea in different cultural settings.

\section{ACKNOWLEDGEMENTS}

This study was conducted as part of a survey in a project by the National Institute of Nutrition (NIN), Viet Nam, International Life Sciences Institute (ILSI) Japan Center for Health Promotion (CHP), and Japan International Cooperation Agency. Sincere appreciation is extended to all the project members. The authors especially thank Mr. Takashi Togami, Director of ILSI Japan CHP; NIN staff members for their advice and cooperation in data collection; and the commune health station staff members for their cooperation. The authors also appreciate the assistance of Ms Nguyen Le Hoa and Ms Bui To Loan in data management. Finally, the authors express special thanks to the colleagues of the Department of Community and Global Health, University of Tokyo, Japan, for their suggestions and encouragement and the children and their mothers who participated in this survey.

\section{REFERENCES}

1. Käferstein F. Foodborne diseases in developing countries: aetiology, epidemiology and strategies for prevention. Int J Environ Health Res 2003;13(Suppl):S161-8.

2. Kosek M, Bern C, Guerrant RL. The global burden of diarrhoeal disease, as estimated from studies published between 1992 and 2000. Bull World Health Organ 2003;81:197-204.

3. United Nations Children's Fund. Database on diarrhoeal disease and ORT. (http://www.childinfo.org/ eddb/Diarrhoea/database.htm, accessed on 4 March 2008).

4. Water Supply and Sanitation Collaborative Council. Listening - to those working with communities in Africa, Asia and Latin America to achieve the UN goals for water and sanitation. Geneva: Water Supply and Sanitation Collaborative Council, 2004:78. (http://www.wsscc.org/pdf/publication/ Listening English_full_pages.pdf, accessed on 4 March 2008).

5. Guerrant DI, Moore SR, Lima AA, Patrick PD, Schorling JB, Guerrant RL. Association of early childhood diarrhea and cryptosporidiosis with impaired physical fitness and cognitive function four-seven years later in a poor urban community in Northeast Brazil. 
Am J Trop Med Hyg 1999;61:707-13.

6. World Health Organization. Food safety and foodborne illness. Geneva: World Health Organization, 2007. (http://www.who.int/mediacentre/factsheets/ fs237/en/print.html, accessed on 4 March 2008).

7. World Health Organization. Basic principles for the preparation of safe food for infants and young children. Geneva: World Health Organization, 1996:1 (WHO/FNU/FOS/96.6).

8. Esrey SA. Food contamination and diarrhoea. World Health 1990 Jan-Feb:19-20.

9. Motarjemi Y, Käferstein F, Moy G, Quevedo F. Contaminated weaning food: a major risk factor for diarrhoea and associated malnutrition. Bull World Health Organ 1993;71:79-92.

10. Barrell RAE, Rowland MGM. Infant foods as a potential source of diarrhoeal illness in rural West Africa. Trans R Soc Trop Med Hyg 1979;73:85-90.

11. Molbak K, Hojlyng N, Jepsen S, Gaarslev K. Bacterial contamination of stored water and stored food: a potential source of diarrhoeal disease in West Africa. Epidemiol Infect 1989;102:309-16.

12. Black RE, Brown KH, Becker S, Abdul Alim ARM, Merson $\mathrm{MH}$. Contamination of weaning foods and transmission of enterotoxigenic Escherichia coli diarrhoea in children in rural Bangladesh. Trans $R$ Soc Trop Med Hyg 1982;76:259-64.

13. Black RE, Lopez de Romana G, Brown KH, Bravo N, Bazalar OG, Kanashiro HC. Incidence and etiology of infantile diarrhea and major routes of transmission in Huascar, Peru. Am J Epidemiol 1989;129:785-99.

14. Afifi ZEM, Nasser SS, Shalaby S, Atlam SAE. Contamination of weaning foods: organisms, channels, and sequlae. J Trop Pediatr 1998;44:335-7.

15. Imong SM, Jackson DA, Rungruengthanakit K, Wongsawasdii L, Amatayakul K, Drewett RF et al. Maternal behaviour and socio-economic influences on the bacterial content of infant weaning foods in rural northern Thailand. J Trop Pediatr 1995;41:234-40.

16. Van Steenbergen WM, Mossel DAA, Kusin JA, Jansen AAJ. Machakos project studies agents affecting health of mother and child in a rural area of Kenya. XXIII bacterial contamination of foods commonly eaten by young children in Machakos, Kenya. Trop Geogr Med 1983;35:193-7.

17. Michanie S, Bryan FL, Alvarez P, Olivo AB, Critical control points for foods prepared in households in which babies had salmonelosis. Int J Food Microbiol 1987;5:337-54.

18. Etiler N, Velipasaoglu S, Aktekin M. Risk factors for overall and persistent diarrhoea in infancy in Antalya, Turkey: a cohort study. Public Health 2004;118:62-9.
19. Oni GA, Schumann DA, Oke EA. Diarrhoeal disease morbidity, risk factors and treatments in a low socioeconomic area of Ilorin, Kwara State, Nigeria. J Diarrhoeal Dis Res 1991;9:250-7.

20. Heller L, Colosimo EA, Antunes CMF. Setting priorities for environmental sanitation interventions based on epidemiological criteria: a Brazilian study. J Water Health 2005;3:271-81.

21. Gorter AC, Sandiford P, Pauw J, Morales P, Perez RM, Alberts $\mathrm{H}$. Hygiene behaviour in rural Nicaragua in relation to diarrhoea. Int J Epidemiol 1998;27:1090-100.

22. Alam N, Wojtyniak B, Henry FJ, Rahaman MM. Mothers' personal and domestic hygiene and diarrhoea incidence in young children in rural Bangladesh. Int J Epidemiol 1989;18:242-7.

23. Alam N, Wai L. Importance of age in evaluating effects of maternal and domestic hygiene practices on diarrhoea in rural Bangladeshi children. J Diarrhoeal Dis Res 1991;9:104-10.

24. Nguyen TV, Van PL, Huy CL, Gia KN, Weintraub A. Etiology and epidemiology of diarrhea in children in Hanoi, Vietnam. Int J Infect Dis 2006;10:298-308.

25. U KM, Khin M, Wai NN, Hman NW, Myint TT, Butler T. Risk factors for the development of persistent diarrhoea and malnutrition in Burmese children. Int J Epidemiol 1992;21:1021-9.

26. Curtis V, Cairncross S. Water, sanitation, and hygiene at Kyoto. BMJ 2003;327:3-4.

27. Curtis V, Cairncross S, Yonli R. Domestic hygiene and diarrhoea-pinpointing the problem. Trop Med Int Health 2000;5:22-32.

28. International Life Sciences Institute Center for Health Promotion of Japan. Project proposal: participatory approach for improvement of safe water supply and health \& sanitation environments with view to attaining better nutrition for children and women in rural areas in Vietnam. Tokyo: International Life Science Institute Center for Health Promotion of Japan, 2004. 10 p. [Japanese].

29. National Institute of Nutrition. Water quality monitoring report, November 2001-October 2002: monitoring and analyze quality of drinking water situation at selected rural areas by pollutants. Hanoi: National Institute of Nutrition, 2003:23-7.

30. Viet Nam. Ministry of Health. Center for Preventive Medicine of Nam Dinh Province. KAP pre-survey report: assessment of knowledge-attitude-practice of community on health and hygiene related to water and sanitation for 5 communes in Vu Ban district, Nam Dinh province, Vietnam. Hanoi: Ministry of Health, Government of Viet Nam, 2003:1-36. 
31. Viet Nam. Ministry of Health. Food Administration. The regulation on food hygiene and safety, 3199/2000/QD-BYT issued on 11 September 2000.

32. World Health Organization. Regional Office for Africa. Health information package, coping with common diseases, diarrhoeal diseases. Brazzaville: Regional Office for Africa, World Health Organization, 2007. (http://www.afro.who.int/afropac/commondiseases/diarrhoea.html, accessed on 4 March 2008).

33. Fewtrell L, Kaufmann RB, Kay D, Enanoria W, Haller L, Colford JM Jr. Water, sanitation, and hygiene interventions to reduce diarrhoea in less developed countries: a systematic review and meta-analysis. Lancet Infect Dis 2005;5:42-52.

34. Rowland MGM, McCollum JPK. Malnutrition and gastroenteritis in the Gambia. Trans $R$ Soc Trop Med Hyg 1977;71:199-203.

35. Black RE, Brown KH, Becker S, Yunus M. Longitudinal studies of infectious diseases and physical growth of children in rural Bangladesh. I. Patterns of morbidity. Am J Epidemiol 1982;115:305-14.

36. Black RE, Brown KH, Becker S, Alim ARMA, Huq I. Longitudinal studies of infectious diseases and physical growth of children in rural Bangladesh. II. Inci- dence of diarrhea and association with known pathogens. Am J Epidemiol 1982;115:315-24.

37. Curtis V, Cairncross S. Effect of washing hands with soap on diarrhea risk in the community: a systematic review. Lancet Infect Dis 2003;3:375-81.

38. Cruz JR, Bartlett AV, Mendez H, Sibrian R. Epidemiology of persistent diarrhea among Guatemalan rural children. Acta Paediatr 1992;381(Suppl):22-6.

39. World Health Organization. Water Supply and Sanitation Collaborative Council. Sanitation and hygiene promotion: programming guidance. Geneva: Water Supply and Sanitation Collaborative Council, World Health Organization, 2005. 10 p. (http://www.who. int/water_sanitation_health/hygiene/sanhygpromo. pdf, accessed on 4 March 2008).

40. Stanwell-Smith R, Bloomfield S. The hygiene hypothesis and implications for home hygiene (A report commissioned by the International Scientific Forum on Home Hygiene). Milano: Arti Grafiche Bazzi, 2004. 40 p.

41. World Health Organization. Five keys to safer food manual. Geneva: World Health Organization, 2006:130. (http://www.who.int/foodsafety/publications/ consumer/manual_keys.pdf, accessed on 4 March 2008). 